\title{
Uji Prestasi Air Heater pada Pelat Bergelombang Melintang dengan Variasi Kecepatan Udara Masuk
}

\author{
Bambang Yunianto, Sumar Hadi Suryo, Dicky Oktavian* \\ Departemen Teknik Mesin, Fakultas Teknik, Universitas Diponegoro \\ Jl. Prof. Sudharto, SH., Tembalang-Semarang 50275, Telp. +62247460059 \\ *E-mail: dicky19oktavian@gmail.com
}

\begin{abstract}
Solar energy is one of the non-conventional renewable energy available freely as an energy source that provides a pollution-free fuel store. The simplest and most efficient way to harness solar energy is to convert it into thermal energy for heating applications using solar collectors. This study discusses the difference in efficiency between plate collector with flat shape and plate with crossed corrugated form. The modification of the heat absorber plate is carried out to improve the heat absorption efficiency. The methods undertaken to obtain the results of this study are to find useful heat values, incoming heat, heat loss, overall heat loss coefficient. The useful heat is the heat generated by the collector during the test. The incoming heat is the heat coming from the halogen lamp that is directed to the collector. The heat loss is heat that can not be maximized by the collector. The overall heat loss coefficient is the heat lost at the top, bottom and side of the collector and the efficiency is the performance result of the collector. The aim of this research is to get the temperature result from 3 sensors located in room, heat absorber plate and collector outlet. Then know the efficiency of the air heater collector from 7 variations of air flow rate are $2.1 \mathrm{~m} / \mathrm{s}, 2.3 \mathrm{~m} / \mathrm{s}, 2.4 \mathrm{~m} / \mathrm{s}, 3 \mathrm{~m} / \mathrm{s}, 3.5 \mathrm{~m} / \mathrm{s}, 4 \mathrm{~m} / \mathrm{s}$, $4.5 \mathrm{~m} / \mathrm{s}$. And the last is to compare the value of collector efficiency of flat plate and crossed corrugated plate. The test results show that the higher crossed corrugated plate plates generate heat than the flat plate and the more air speed increases the efficiency will also increase.
\end{abstract}

Keywords: Flat plate, Crossed corrugated plate, Air flow rate, Temperature, Efficiency

\section{Abstrak}

Energi surya merupakan salah satu energi terbarukan non-konvensional yang tersedia secara bebas sebagai sumber energi yang memberikan simpanan bahan bakar bebas polusi. Cara yang paling sederhana dan paling efisien untuk memanfaatkan energi surya adalah mengubahnya menjadi energi termal untuk aplikasi pemanasan dengan menggunakan kolektor surya. Penelitian ini membahas tentang perbedaan efisiensi antara kolektor pelat dengan bentuk datar dan pelat dengan bentuk gelombang melintang. Modifikasi dari pelat penyerap panas tersebut dilakukan untuk meningkatkan efisiensi penyerapan panas. Metode yang dilakukan untuk mendapatkan hasil dari penelitian ini adalah dengan mencari nilai panas yang berguna, panas yang masuk, panas yang hilang, koefisien panas yang hilang secara keseluruhan. Panas yang berguna merupakan panas yang dihasilkan oleh kolektor pada saat pengujian. Panas yang masuk adalah panas yang berasal dari lampu halogen yang ditujukan ke kolektor. Panas yang hilang adalah panas yang tidak dapat dimaksimalkan oleh kolektor. Koefisien panas yang hilang secara keseluruhan adalah panas yang hilang pada bagian atas, bawah dan samping kolektor dan efisiensi adalah hasil kinerja dari kolektor. Penelitian ini bertujuan untuk mendapatkan hasil temperatur dari 3 buah sensor yang berada pada ruangan, pelat penyerap panas dan tempat keluar kolektor. Kemudian mengetahui efisiensi kolektor pemanas udara dari 7 variasi kecepatan udara yaitu $2.1 \mathrm{~m} / \mathrm{s}, 2.3 \mathrm{~m} / \mathrm{s}, 2.4 \mathrm{~m} / \mathrm{s}, 3 \mathrm{~m} / \mathrm{s}, 3.5 \mathrm{~m} / \mathrm{s}, 4 \mathrm{~m} / \mathrm{s}, 4.5 \mathrm{~m} / \mathrm{s}$. Terakhir adalah membandingkan nilai efisiensi kolektor pelat datar dan pelat gelombang melintang. Hasil pengujian menunjukkan bahwa pelat gelombang melintang lebih tinggi menghasilkan panas dibanding pelat datar dan semakin meningkat kecepatan udara maka efisiensi juga akan meningkat.

Kata kunci: Pelat datar, Pelat gelombang melintang, Kecepatan udara, Temperatur, Efisiensi.

\section{Pendahuluan}

Energi dalam berbagai bentuk telah memainkan peran penting dalam kemajuan ekonomi dan industri di seluruh dunia. Sumber utama energi ini berasal dari cadangan bahan bakar fosil. Dengan semakin berkurangnya bahan bakar fosil di dunia sebagai sumber energi, mendorong dilakukan pengembangan sumber energi terbarukan non-konvensional. Energi surya merupakan salah satu energi terbarukan non-konvensional yang tersedia secara bebas sebagai sumber energi yang memberikan simpanan bahan bakar bebas polusi. Cara yang paling sederhana dan paling efisien untuk 
memanfaatkan energi surya adalah mengubahnya menjadi energi termal untuk aplikasi pemanasan dengan menggunakan kolektor surya [1].

Pemanfaatan energi surya banyak digunakan dalam pemanas udara surya (solar air heater) karena sederhana dan murah. Aplikasi pemanas udara surya adalah sebagai pemanas ruangan, untuk mengeringkan produk industri, dan dapat digunakan secara efektif untuk pengeringan komponen bangunan yang terbuat dari beton atau tanah liat. Pemanas udara surya memiliki kelebihan dalam hal penggunaan material dan biaya yang minimal [2].

Modifikasi pada pemanas udara surya memiliki tujuan untuk menaikkan nilai efisiensi termal. Ada dua metode dasar untuk meningkatkan nilai efisiensi termal pada pemanas udara surya. Metode pertama melibatkan peningkatan luas permukaan perpindahan panas dengan menggunakan permukaan bergelombang (corrugated surfaces) atau permukaan yang diperluas dengan menggunakan sirip-sirip (fins) tanpa mempengaruhi koefisien perpindahan panas konveksi. Metode kedua melibatkan peningkatan perpindahan panas konveksi dengan menciptakan turbulensi di permukaan perpindahan panas. Hal ini dapat dicapai dengan memberikan kekasaran buatan (artificial roughness) pada pelat penyerap dan pemasangan vortex generator [3]. Material yang digunakan untuk pelat penyerap yaitu jenis logam berupa aluminium [4].

Cara kerja kolektor pemanas udara adalah dengan mengumpulkan energi panas dari matahari dengan cara radiasi, kemudian panas akan diserap oleh pelat dan kemudian pelat mentransfer energi panas ke udara dengan bantuan fan melalui proses konveksi paksa. Pelat penyerap dicat dengan warna hitam untuk menyerap radiasi matahari karena warna hitam memiliki nilai emisivitas yang sempurna untuk penyerapan radiasi. Pelat penyerap kemudian dilapisi dengan isolator untuk mengurangi panas yang hilang [5]. Semakin tinggi nilai konduktivitas termal suatu material, maka proses penyerapan panas akan semakin tinggi [6].

Penelitian ini bertujuan untuk mengetahui perbedaan efisiensi antara kolektor pelat dengan bentuk datar dan pelat dengan bentuk gelombang melintang. Modifikasi dari pelat penyerap panas tersebut dilakukan untuk meningkatkan efisiensi penyerapan panas. Penelitian ini dilakukan dengan memvariasikan kecepatan aliran udara lewat kolektor. Sebagai langkah awal penelitian digunakan pemanas simulator surya sebagai ganti pemanas dengan energi surya langsung.

\section{Material dan Metode Penelitian}

\subsection{Alat \& Bahan}

Bahan yang digunakan pada pengujian kolektor pemanas udara adalah:

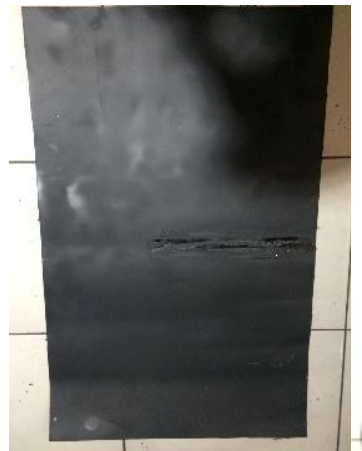

(a)

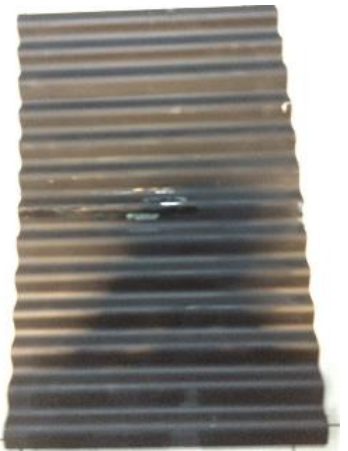

Gambar 1. Bahan yang digunakan:

(b)

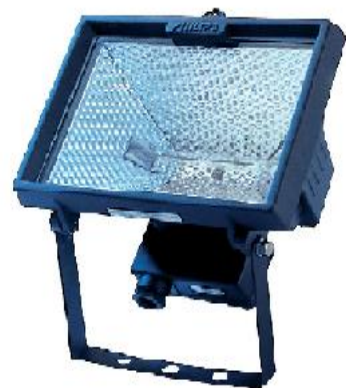

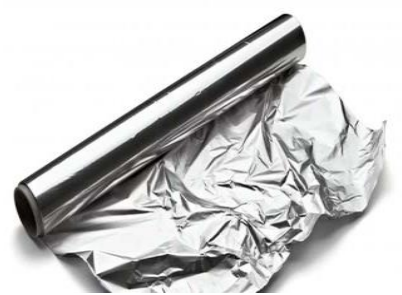

(c)

Gambar 1(a) merupakan pelat yang berfungsi untuk menyerap panas dan sebagai pembanding yang berbentuk datar dan gelombang melintang berbahan seng untuk menciptakan aliran turbulen [7]. Gambar 1(b) adalah lampu halogen digunakan sebagai sumber panas sebagai simulator energi matahari untuk memanaskan pelat yang akan dikontakkan dengan udara dalam kolektor pemanas udara karena daya dari lampu halogen mendekati dengan daya yang dipancarkan oleh matahari. Lampu halogen yang digunakan 2 buah dengan masing-masing daya 500 Watt, panas yang masuk dari lampu halogen menuju pelat penyerap sangat berpengaruh pada proses pemanasan berlangsung. Gambar 1(c) Aluminium foil digunakan sebagai isolator dan reflektor dipasang dibawah pelat penyerap panas dan bagian samping kolektor agar panas yang diserap dapat maksimal dan panas tidak keluar dari tempat kolektor penyerap panas, aluminium foil digunakan karena bahan yang murah dan mudah didapatkan di pasaran.

Gambar 2(a) exhaust fan digunakan untuk menghisap udara dari luar atau udara yang telah disirkulasikan ke dalam ruangan. Exhaust fan yang digunakan adalah dengan dimensi 120x120x38 mm. Spesifikasi exhaust fan yang digunakan dalam pengujian sebagai berikut merk: Happy, voltage: $220 \mathrm{~V}$, frequency: $50 \mathrm{~Hz}$. Gambar 2(b) adalah termokopel tipe K merupakan jenis sensor temperatur yang menggunakan bahan berupa nikel-kromium, sangat akurat dalam pengukuran temperatur, sangat murah dan mudah didapat. Sensor termokopel dipasang pada bagian pelat penyerap panas, pada bagian tempat keluar kolektor, dan pada bagian ruangan tempat pengujian berlangsung. Gambar 2(c) modul portabel akusisi data, modul ini berfungsi untuk mengakusisi atau merekam data hasil pengukuran parameter oleh sensor yang 
dipasang, lalu memproses data tersebut dan mengirimkan data yang sudah diproses ke komputer untuk mengetahui data parameter yang diambil dan hasil yang didapatkan pada sensor termokopel. Modul portabel ini bertipe USB-4718 dengan merk Advantech. Gambar 2(d) Komputer berfungsi untuk memproses data dari data portabel dan menampilkan hasil pengukuran dari penelitian yang berlangsung, komputer harus terlebih dahulu di install software yang mendukung program pengaplikasian agar hasil dari pengukuran termokopel dapat terbaca dan dilihat langsung pada saat pengujian. Gambar 2(e) adalah hot wire anemometer digunakan untuk mengukur kecepatan udara yang mengalir pada kolektor pemanas udara. hot wire anemometer yang digunakan bermerk Lutron AM-4204 dengan spesifikasi pengukuran rentang hingga $20.0 \mathrm{~m} / \mathrm{s}$, pengukuran suhu operasi hingga $50^{\circ} \mathrm{C} / 122^{\circ} \mathrm{F}$, kombinasi kawat panas dan standar termistor, memberikan pengukuran yang cepat dan tepat bahkan pada nilai kecepatan udara rendah, microprocessor circuit, dapat mengukur satuan $\mathrm{m} / \mathrm{s}, \mathrm{km} / \mathrm{h}, \mathrm{ft} / \mathrm{min}$, knot, dan mile/h. Gambar 2(f) adalah regulator, fungsi dari regulator yaitu untuk mengatur jumlah aliran listrik yang masuk dari sumber listrik melalui rangkaian yang dibuat. Tujuannya yaitu untuk mengatur jumlah listrik yang masuk ke exhaust fan untuk mengatur kecepatan udara yang diinginkan. Regulator yang digunakan bermerk Krisbow KW2001220 analog voltage regulator dengan daya 1 KVA dengan tipe KW2001221.

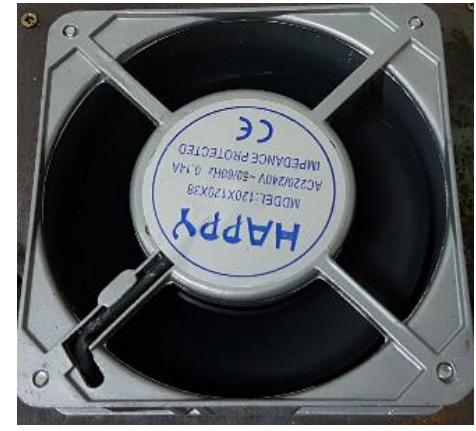

(a)

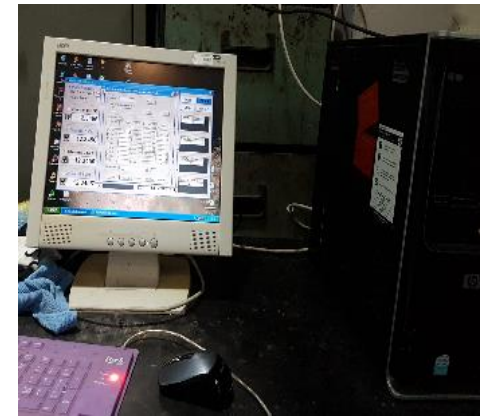

(d)

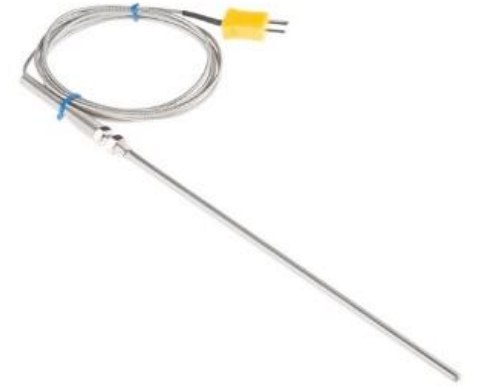

(b)

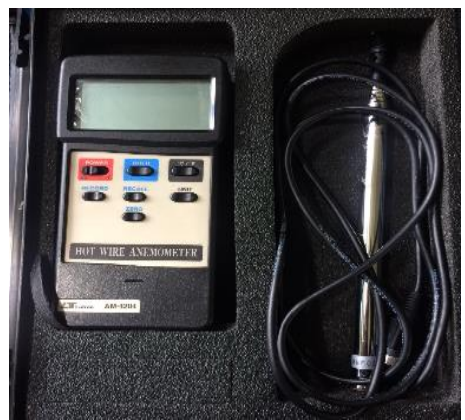

(e)

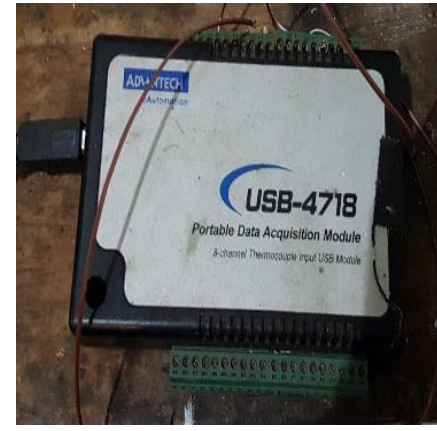

(c)

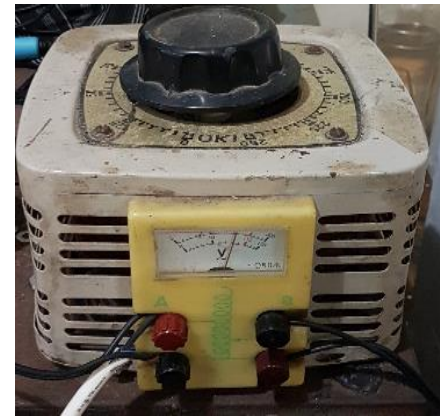

(f)

Gambar 2. Alat yang digunakan (a). Exhaust Fan, (b). Termokopel Tipe K, (c). Modul Portabel Akusisi Data, (d). Komputer, (e). Hot Wire Anemometer \& (f). Regulator

\subsection{Metodologi Penelitian}

Pada Gambar 3 proses pertama yang dilakukan adalah studi literatur dimana mencari, mencermati dan mempelajari jurnal-jurnal yang berhubungan dengan topik yang diambil, selanjutnya mulai mendesain kolektor pemanas udara yang ingin dibuat kemudian mengambil keputusan apakah jika komponen sesuai alat yang dipasaran dengan hasil desain alat yang telah dibuat, jika ya maka lanjut ke proses penyesuaian bentuk, ukuran dan komponen yang tersedia dimana mencari material, alat dan bahan yang ingin digunakan untuk membuat alat kolektor pemanas udara, jika tidak kembali mendesain alat kolektor pemanas udara. Proses selanjutnya yaitu melanjutkan pembuatan kolektor pemanas udara setelah itu mengambil keputusan apakah alat beroperasi dengan baik, jika tidak maka kembali membuat alat kolektor pemanas udara dengan mencari material dan komponen yang sesuai, jika ya maka lanjut ke proses pengujian untuk memperoleh temperatur dan nilai efisiensi kolektor, jika hasil dari pengujian telah didapatkan dan hasil yang didapatkan sudah benar maka setelah itu masuk ke proses pengolahan data dimana melakukan perhitungan pada hasil pengujian. Sesudahnya dari pengolahan data maka didapatkan hasil dan pembahasan dari pengujian yang dilakukan kemudian melakukan proses pengambilan kesimpulan dan saran yang didapat pada saat pengolahan data, kemudian selesai. Pada penelitian ini langkah-langkah penelitian mengacu pada diagram alir berikut: 


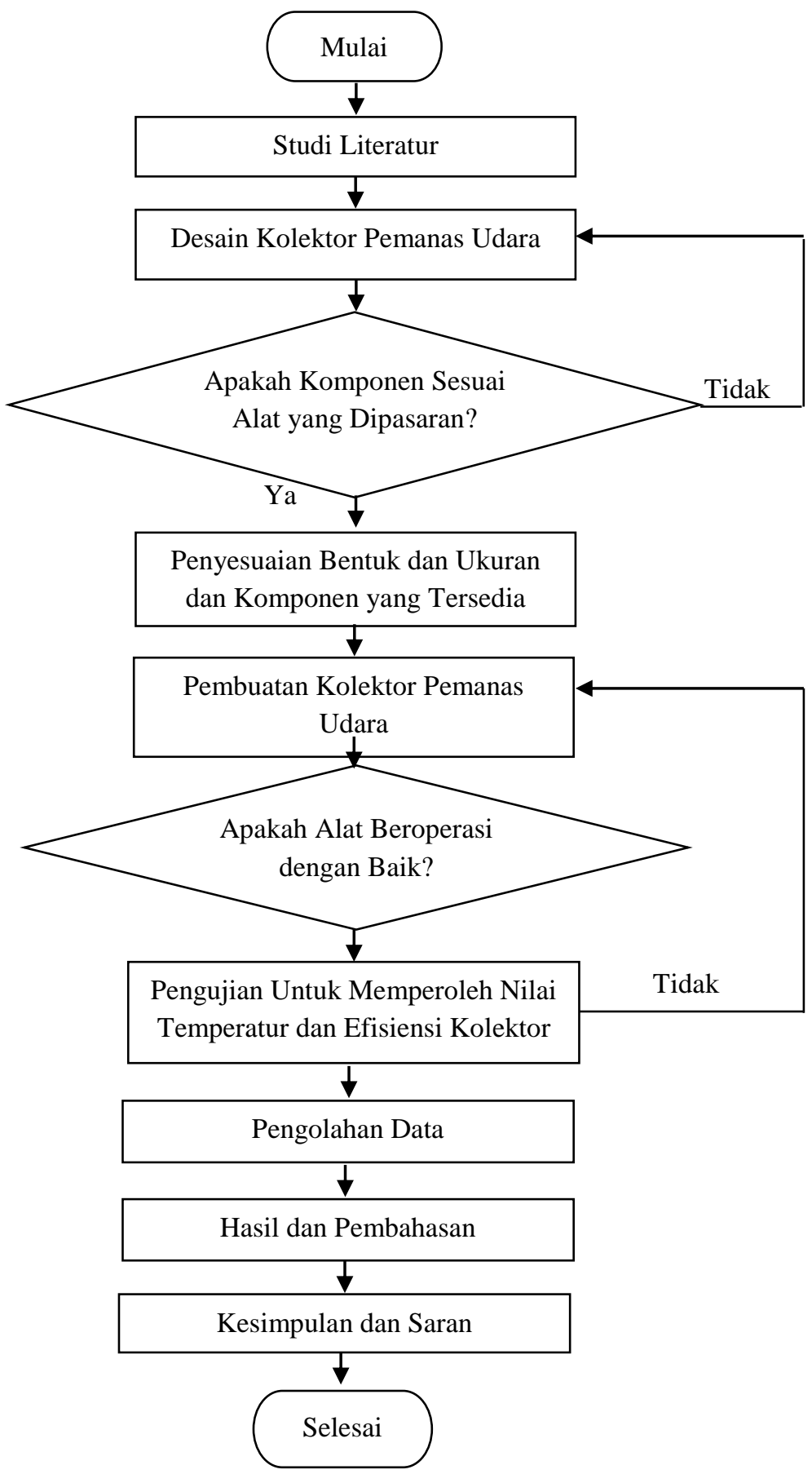

Gambar 3. Diagram Alir Penelitian

\subsection{Perhitungan yang Digunakan}

\section{(a) Panas Yang Berguna}

Panas yang berguna adalah panas yang berhasil dimaksimalkan kolektor dan digunakan untuk aplikasi pemanasan dinyatakan sebagai berikut [8]:

$$
\mathrm{Q}_{\mathrm{U}}=\dot{\mathrm{m}}_{\mathrm{udara}} * \mathrm{C}_{\mathrm{p}_{\text {,udara }}} *\left(\mathrm{~T}_{\text {out }}-\mathrm{T}_{\text {in }}\right)
$$

dimana:

$$
\begin{array}{ll}
\dot{m}_{\text {udara }} & =\text { Laju aliran massa udara }(\mathrm{kg} / \mathrm{s}) \\
C_{P_{\text {uddara }}} & =\text { Kapasitas panas spesifik udara }(\mathrm{J} / \mathrm{Kg} * \mathrm{~K}) \\
T_{\text {out }} & =\text { Temperatur udara keluar }\left({ }^{\circ} \mathrm{K}\right)
\end{array}
$$


$T_{\text {in }} \quad=$ Temperatur udara masuk $\left({ }^{\circ} \mathrm{K}\right)$

\section{(b) Panas Yang Masuk}

Panas yang masuk adalah panas yang berasal dari lampu halogen yang masuk menuju pelat penyerap panas dinyatakan sebagai berikut [9]:

$$
\begin{aligned}
& \text { Ic. } A c=F_{1-2} * P_{\text {Lampu }} \\
& \text { dimana: } \\
& \text { Ic. } A c=\mathrm{F}_{1-2} * \mathrm{P}_{\text {Lampu }} \\
& \mathrm{F}_{1-2}=\text { Faktor bentuk permukaan } \\
& \mathrm{P}_{\text {Lampu }}=\text { Daya lampu halogen (Watt) }
\end{aligned}
$$

\section{(c). Panas Yang Hilang}

Panas yang hilang pada kolekor pemanas udara tersebut terjadi pada 3 bagian, yaitu panas hilang pada bagian bawah kolektor, panas hilang pada bagian atas kolektor, dan panas hilang pada bagian samping kolektor, rumus panas yang secara keseluruhan dinyatakan sebagai berikut [8]:

$$
\begin{aligned}
& \hat{\mathrm{Q}}_{\mathrm{Loss}}=\mathrm{Ic} \cdot \mathrm{Ac}-\dot{\mathrm{Q}}_{\mathrm{U}} \\
& \text { dimana : } \\
& \text { Ic. } A c \text { = Panas yang masuk (Watt) } \\
& \dot{Q}_{U} \quad=\text { Panas yang berguna (Watt) }
\end{aligned}
$$

\section{(d). Efisiensi}

Analisa tentang kinerja alat terhadap hasil data temperatur yang dihasilkan, menentukan perfomansi alat kolektor pemanas udara. Perfomansi kolektor pemanas udara disebut efisiensi, yang dinyatakan sebagai berikut [10]:

$$
\eta_{\text {Collector }}=\frac{Q_{U}}{I c \cdot A c} * 100 \%
$$

dimana:

$$
\begin{aligned}
& \dot{Q}_{U}=\text { panas yang berguna pada proses kolektor pemanas udara (Watt) } \\
& I c \cdot A c \\
& \quad=\text { panas yang masuk ke kolektor pemanas udara (Watt) }
\end{aligned}
$$

\section{Hasil dan Pembahasan}

\subsection{Hasil Pengujian Pelat Datar}

Grafik efisiensi yang didapatkan pada pelat datar pada kecepatan $2.1 \mathrm{~m} / \mathrm{s}, 2.3 \mathrm{~m} / \mathrm{s}, 2.4 \mathrm{~m} / \mathrm{s}, 3 \mathrm{~m} / \mathrm{s}, 3.5 \mathrm{~m} / \mathrm{s}, 4 \mathrm{~m} / \mathrm{s} \mathrm{dan}$ $4.5 \mathrm{~m} / \mathrm{s}$.

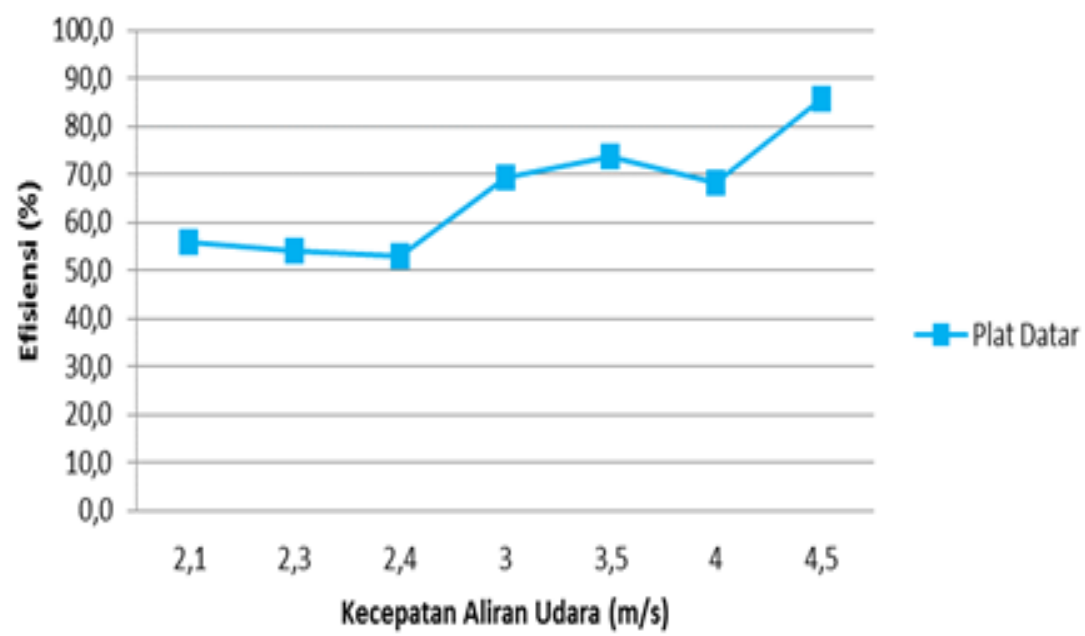

Gambar 4. Grafik Efisiensi Pelat Datar 
Gambar 4 menunjukkan hubungan antara efisiensi pelat datar terhadap kecepatan aliran udara. Dapat dianalisa semakin bertambahnya kecepatan aliran udara maka efisiensi dari pelat datar akan semakin meningkat. Tetapi ada di kecepatan aliran udara tertentu efisiensi menjadi turun hal ini disebabkan oleh pengaruh besar panas yang berguna menurun. Contohnya pada kecepatan $2.3 \mathrm{~m} / \mathrm{s}$ ke $2.4 \mathrm{~m} / \mathrm{s}$ efisiensi menurun sebesar $1 \%$ dan pada kecepatan $3.5 \mathrm{~m} / \mathrm{s} \mathrm{ke} 4$ $\mathrm{m} / \mathrm{s}$ efisiensi menurun sebesar $5,3 \%$.

\subsection{Hasil Pengujian Pelat Gelombang Melintang}

Grafik efisiensi yang didapatkan pada pelat gelombang melintang pada kecepatan $2.1 \mathrm{~m} / \mathrm{s}, 2.3 \mathrm{~m} / \mathrm{s}, 2.4 \mathrm{~m} / \mathrm{s}, 3 \mathrm{~m} / \mathrm{s}$, $3.5 \mathrm{~m} / \mathrm{s}, 4 \mathrm{~m} / \mathrm{s}$ dan $4.5 \mathrm{~m} / \mathrm{s}$

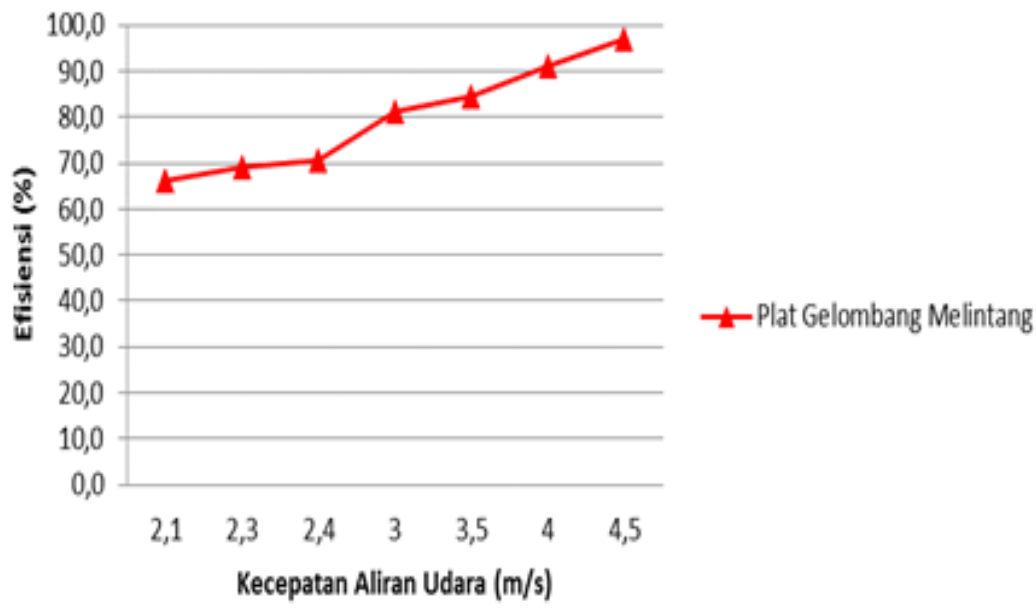

Gambar 5. Grafik Efisiensi Pelat Gelombang Melintang

Gambar 5 menampilkan hubungan antara efisiensi pelat gelombang melintang terhadap kecepatan aliran udara, dapat dilihat semakin meningkatnya kecepatan aliran udara maka efisiensi dari pelat gelombang melintang akan semakin meningkat. Kenaikkan efisiensi tertinggi terjadi pada kecepatan $2.4 \mathrm{~m} / \mathrm{s} \mathrm{ke} 3 \mathrm{~m} / \mathrm{s}$ yaitu sebesar 10,7 \%.

\subsection{Hasil Perbandingan Efisiensi Pelat Datar dan Pelat Gelombang Melintang}

Grafik perbandingan efisiensi yang didapatkan pada pelat datar dan gelombang melintang pada kecepatan $2.1 \mathrm{~m} / \mathrm{s}$, $2.3 \mathrm{~m} / \mathrm{s}, 2.4 \mathrm{~m} / \mathrm{s}, 3 \mathrm{~m} / \mathrm{s}, 3.5 \mathrm{~m} / \mathrm{s}, 4 \mathrm{~m} / \mathrm{s}$ dan $4.5 \mathrm{~m} / \mathrm{s}$.

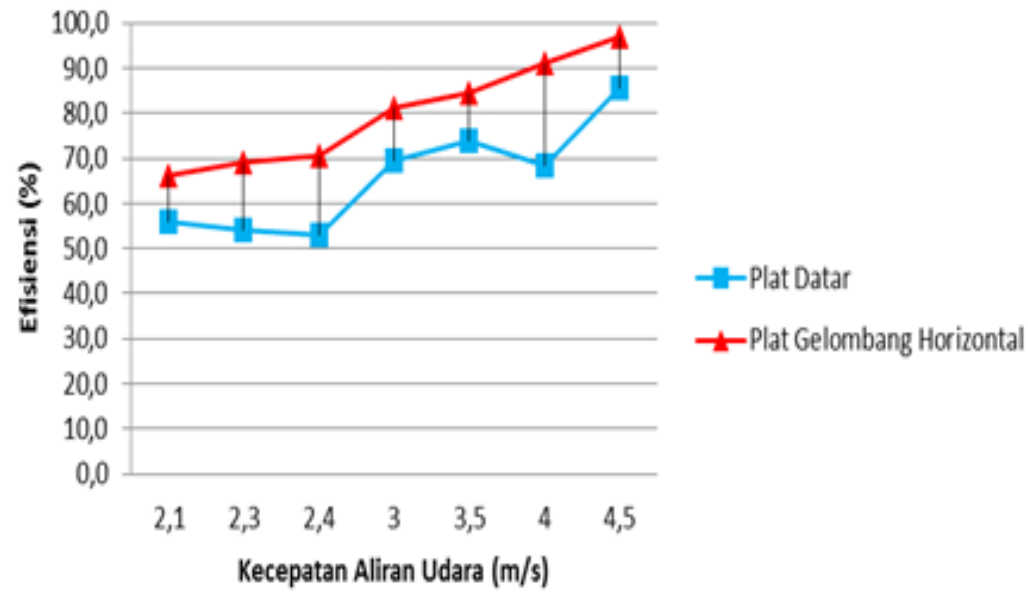

Gambar 6. Grafik Perbandingan Efisiensi Pelat Datar dan Gelombang Melintang

Gambar 6 dapat dilihat efisiensi tertinggi pelat datar yakni sebesar 85,6\% dan efisiensi tertinggi pada pelat gelombang melintang sebesar $96,8 \%$ pada kecepatan udara $4.5 \mathrm{~m} / \mathrm{s}$. Sehingga dapat dianalisa efisiensi yang terjadi pada masing-masing pelat berbanding lurus terhadap kecepatan udara walaupun kenyataannya garis yang terbentuk tidak linier sempurna. Faktor terjadi penurunan efisiensi disebabkan oleh kecepatan yang tidak selalu konstan dan dipengaruhi oleh temperatur ruangan, pelat dan keluar kolektor mengakibatkan hasil efisiensi menjadi naik turun, dan juga dipengaruhi oleh posisi peletakan sensor yang kurang baik sehingga menimbulkan kesalahan pengukuran. 


\section{Kesimpulan}

Pengujian pada pelat datar dapat menghasilkan temperatur pada pelat tertinggi sebesar $90{ }^{\circ} \mathrm{C}$, untuk pelat gelombang melintang temperatur pada pelat tertinggi sebesar $97{ }^{\circ} \mathrm{C}$, untuk temperatur ruangan tertinggi pada saat melakukan pengujian kedua pelat tersebut sebesar $32{ }^{\circ} \mathrm{C}$ dan untuk temperatur keluar kolektor tertinggi pada saat pengujian pelat datar adalah sebesar $47{ }^{\circ} \mathrm{C}$ dan untuk pelat gelombang melintang sebesar $50{ }^{\circ} \mathrm{C}$. Jika variasi laju kecepatan udara meningkat maka efisiensi dari kolektor juga akan meningkat, efisiensi tertinggi yang diperoleh pelat datar adalah sebesar $85,6 \%$ dan pada pelat gelombang melintang sebesar 96,8\%. Pelat gelombang melintang menghasilkan panas yang lebih tinggi dibandingkan dengan pelat datar.

\section{Daftar Pustaka}

[1] Chabane, F., Moummi, N., Benramache, S., Bensahal, D. and Belahssen, O. 2013, "Collector Efficiency by Single Pass of Solar Air Heaters with and without Using Fins", Engineering Journal, vol. 17, no. 3, pp. 1-13.

[2] Koolnapadol, N., Promvonge, P. and Skullong, S. 2017, "Performance Assessment of Solar Air Heater Duct Roughened With Perforated-Winglet Vortex Generators". International Journal of Smart Grid and Clean Energy, vol. 6, no. 1, pp. 31-39.

[3] Anil, S, Y., Manish, K, T. 2016, "Artificially Roughened Solar Air Heater: A Comparative Study”. International Journal of Green Energy, vol. 13, no. 2, pp. 143-172.

[4] Pal, V., Rai, K, A., Sachan, V. 2015, "Performance Study Of Solar Air Heater". International Journal of Mechanical Engineering and Technology, vol. 6, no. 7, pp. 01-07.

[5] Çaglayan, N., Alta, D, Z., Ertekin, C. 2014, "Experimental Investigation of Various Type Absorber Plates for Solar Air Heaters". Journal of Agricultural Sciences, vol. 21, pp 459-470.

[6] Irawan, R. 2016, "Pembuatan Dan Pengujian Kolektor Surya Pelat Datar (Flat-Plate Collectors) Kondisi Steady Berdasarkan Standar EN 12975”. Fakultas Teknik, Universitas Lampung, Bandar Lampung.

[7] Bejan, Adrian, Kraus, Alan, D. 1948, "Heat Transfer Handbook". John Wiley \& Son, New York.

[8] Duffie, William, A, Beckman, A, W. 1980, "Solar Engineering Of Thermal Processes". Jhon Wiley \& Son, New York.

[9] Incropera and Dewit. 1996, "Fundamentals of Heat and Mass Transfer". John Wiley \& Sons, New York.

[10] Holman, J, P. 1983, “Heat Transfer Sixth Edition”. McGraw Hill, London. 